major modifications of the currents in the northern and middle reaches of the North Sea half a year earlier.

The results obtained from the current measurements in question have been applied to various problems of fishery interest. Amongst those of immediate local concern, that is, germane to the southern North Sea, there are the questions of good and bad survival years for the plaice and for the herring of the great East Anglian autumn fishery. The latter originate from vast annual spawnings in the eastern end of the Channel. It seems that good fortune has attended the broods of both fish when, during the egg and/or fry stages, the current issuing from Dover Straits has been most average in point both of strength and direction. This accords with the supposition that good augury for a plaice brood exists when the products of the spawning are transported to the Continental coastal shallows-the so-called young plaice nursery grounds.

Other problems calling for the application of the Varne lightvessel current data in their local rôle are concerned with the intermingling of two types of herring through the Straits, and with the outcome of the Belgian spent herring fishery. This latter is carried out upon fish supposedly enfeebled by the operation of spawning in the eastern channel.

Applied at a distance as it were, on the strength of the facts set out above, the Dover Straits current data enable something to be said about good and poor haddock years. The haddock fluctuates very closely (though oppositely) with the herring, and seems, when in the egg and fry stage, to have experienced the best survival conditions when we should judge the waters to have been most strongly urged towards the south.

The year-class fluctuations of the cod have been studied side by side with meteorological data, and it appears that the best augury for a brood obtains in those spawning seasons during which winds from the half-compass centred on north-east have been at a maximum-a finding which accords well with what is inferred in the case of the haddock from the Varne current data.
G. A. S.

\title{
Translocation in the Cotton Plant
}

$\mathrm{T}$ $\mathrm{HE}$ cotton plant continues to be a fruitful source of information regarding the movement of materials in plants. Phillis and Mason", in a paper which deals more particularly with the transport of carbohydrate out of the leaves into the vascular tissue, have re-examined the evidence which led Mason and Maskell ${ }^{2}$ to the conclusion that carbohydrate was exported from the mesophyll as reducing sugar and condensed to sucrose in the phloem of the transporting tissue, and that carbohydrate is translocated in the form of sucrose along concentration gradients in the phloem.

The results of Phillis and Mason, derived from an elaborate series of ringing experiments and determinations of diurnal fluctuations in the concentration of sugars in the lamina and petiole, indicate that sucrose, and not reducing sugar, is the form in which carbohydrate is moved from the mesophyll to the veins as well as longitudinally down the petiolar phloem. They find further that the concentration of sucrose is greater in the vein and petiole than in the mesophyll, suggesting that sucrose is accumulated against a concentration gradient. By subdividing the petiole into wood and inner and outer bark, they concluded that this accumulation occurred in the phloem region, and an examination of the distribution of sieve-tubes and companion cells indicated the localisation of the process in the large companion cells and undivided phloem mother cells of the fine veins. These 'transition cells' thus remove sucrose from the leaf parenchyma and liberate it to the sieve tubes of the veins, whence it is transported by a diffusion process down concentration gradients. The problem of translocation is thus further complicated by the additional problem of accumulation against a concentration gradient, a mechanism which is far from being completely understood even in the case of much simpler substances than sucrose.

No. 5 of the Memoirs of the Cotton Research Station, Trinidad, 1934, contains two further papers by Mason and Maskell. The first ${ }^{3}$ deals with the transport of phosphorus, potassium, calcium and nitrogen. The results indicate that these elements move upward in the xylem, and with the exception of calcium, are re-exported from the leaf and move downwards in the phloem. Estimations of the ratios of nitrogen, phosphorus and potassium to carbohydrate moving downwards from the leaves indicate that these elements are probably in excess of the amounts required for growth of the lower tissues. It is suggested that mineral elements ascend the stem from the roots with the transpiration current, passing with the bulk of the water to the leaves, where accumulation occurs together with the synthesis of organic compounds. Downward movement of these mineral substances is accompanied by leakage laterally, not only to the growing and storage tissues but also into the trachex, in which they may be moved upward again by the transpiration stream. Calcium was not appreciably re-exported from the leaf and seems incapable of moving in the phloem, facts which the authors suggest may be correlated with the combination of this element with cell contents, or the relative impermeability of the cell membranes.

The other paper* consists of the examination of changes in the concentrations and vertical gradients of mineral elements and carbohydrates in relation to ontogeny, the object being to derive evidence to show whether transport occurs by a diffusion mechanism determined by individual concentration gradients for each substance moved or by "a mass flow of sap containing all the mobile materials" from a region of higher to one of lower turgor pressure. Negative gradients from the foliage region downwards were found for nitrogen, phosphorus, potassium and calcium, but it is suggested that the "dynamic gradient of mobile material was being masked by a static gradient of storage or immobile material".

In the case of nitrogen, a positive gradient of residual nitrogen is shown to be almost completely masked by the storage of asparagine, which results in a steep negative gradient of crystalloid nitrogen. Except in the case of potassium, the evidence for 
positive gradients of the mineral elements is not conclusive, the ontogeny showing storage of calcium, initial storage of phosphorus followed by depletion, and no storage of potassium. The gradients are consequently negative in the two former cases and positive for potassium. The observed positive gradient of total osmotic pressure in the bark would seem to lend support either to a diffusion or a mass flow mechanism. The authors claim, however, that the data in general support the view that "move. ment of materials along the phloem is determined independently for each material by the concentration gradient of its mobile form in the channel of transport".

W. E. B.

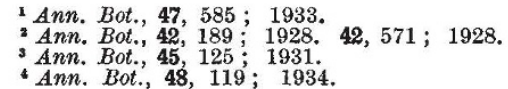

\section{University and Educational Intelligence}

WALES.-The Council of University College, Cardiff, has made the following appointments: Mr. E. E. Edwards, adviser in agricultural zoology; Dr. Dorothy Strangeways, assistant lecturer in histology ; Dr. R. W. Haines, assistant lecturer in anatomy; Mr. C. W. Startup, assistant lecturer in physiology.

The Council has awarded the Dr. Price prize in anatomy to Mr. Henry Vernon Jones.

Charles W. Eliot, the Harvard president who did so much during his forty years of office to make his University famous, has been the subject of many addresses and articles commemorating his birth a hundred years ago. One of these, by the present head of the University, Dr. J. B. Conant, published in School and Society of April 7, emphasises the unusual combination exhibited in his character of rigid principles and invincible faith and courage with a power of mental growth persisting through a great part of his career. This power was exemplified in the reshaping of his original conception of the function of a university as primarily "regular and assiduous class teaching". Influenced in part by the ideas which guided his friend Gilman in inaugurating advanced study and research work at Johns Hopkins University in 1876, he came to recognise graduate work as essential to the idea of a university. There is an element of irony in the juxtaposition in another issue of the same journal of a quotation from one of Eliot's latest pronouncements on education and a paper read before the Association of American Universities at its last annual conference on the "alarming growth" of graduate work in institutions not designed and equipped for it and in many instances not even fully qualified for work of the college grade. It appears that some 20,000 awards of the master's degree are now made annually and it becomes increasingly difficult to protect even the Ph.D. against inflation. Recent investigations show that, without counting teacher-training departments of universities, there are 233 graduate schools, of which no more than 27 have been deemed eligible to membership of the Association of American Universities, while, to make matters worse, additional institutions of undergraduate calibre are constantly breaking into the graduate field, and the aggregate enrolment in these pseudo-graduate schools, some of which have the effrontery to offer a doctorate, is mounting at an amazing rate.

\section{Science News a Century Ago}

\section{Halley's Comet}

A century ago, much interest was shown in the approaching reappearance of Halley's comet, which had last been seen in 1759. Damoiseau in Italy, Pontecoulant in France and Lehmann and Rosenberger in Germany had all made calculations regarding it, and had shown that it would be visible again in the latter part of 1835. An American paper, however-the New York Commercial Advertiser-an. nounced in the late summer of 1834 that Halley's comet was visible in the east, near the constellation Taurus, and that its distance from the earth was $40,000,000$ miles. It also said that on September 13 the comet would be only $22,000,000$ miles distant and that on October 6 it would be nearest the earth, being then only three and a half million miles distant. The announcement was reprinted in the Times of October 6, 1834, and it was followed a few days later by a note from an Irish paper in which a correspondent pointed out that the comet would not be seen until a year later. As a matter of fact, the comet was first observed from the Jesuit Observatory in Rome on August 5, 1835.

\section{Invention of a Sphygmometer}

In the Times of October 6, 1834, it is recorded that at a meeting of the Paris Academy of Sciences, Dr. Magendie made a report upon an instrument invented by Dr. Hérisson called the 'sphygonemètre' which shows the rate of the pulse, its rhythms and anomalies. In pursuance of the conelusion of the reporter, the Academy passed a vote of thanks to the author of this most useful and ingenious discovery. Dr. Hérisson published a memoir, showing the results of his several applications of this instrument in studying the diseases of the heart. After six years of clinical researches supported by numerous anatomical proofs, he claimed that it was capable of distinguishing organic affections from cases which only assume the appearance of such affections. As the sphygmometer gave the numerical force of the pulse, it was possible, according to the observations of Dr. Hérisson, to prevent such attacks of apoplexy as arise from a too great determination of the blood towards the head.

\section{The Dublin and Kingstown Railway}

The first railway in Ireland was that from Dublin to Kingstown constructed by C. B. Vignoles (17931875 ) and the first train ran on October 9,1834 . The following comments are from Saunder's Dublin News Letter (Oct. 10, 1834). "Yesterday, Oct. 9, a train of carriages proceeded for the first time from the station house at Westland Row to Salt-hill. A great number of ladies and gentlemen, invited by the directors, enjoyed this so novel a treat in this country.". Two trips were made, the train being drawn in the first instance by the locomotive Hibernia built by Sharp, Roberts and Co., of Manchester, and in the second by the locomotive Vauxhall built by Messrs. Forester and Co., of the Vauxhall Foundry, Liverpool. Among other remarks it was said that, "nothing could surpass the admirable manner in which the spiral springs which are attached to the buffers ward off the concussion when the train is stopped. . . Every person who joined in the trip was delighted with the perfect ease to themselves. 